\title{
O DESASTRE BIOLÓGICO DA COVID-19 E OS IMPACTOS DA INFODEMIA NA GESTÃO SOCIOAMBIENTAL DO RISCO
}

\author{
Gabriela Marchesan Antoniazz ${ }^{1}$; Francielle Benini Agne Tybusch ${ }^{2}$
}

\section{RESUMO}

O presente artigo científico trata sobre o desastre biológico da covid-19 e os impactos da infodemia na gestão ambiental. Remete à discussão acerca da responsabilidade de como se divulga essas informações, como as formas de prevenção, vacina, métodos chegam até os cidadãos, e entre eles, as fake news e as infodemias. O quão agrava os casos do corona vírus, devido ao acúmulo de infodemias, onde tendo como propósito o direito à informação, mas acaba sendo de uma forma desequilibrada, pelo fato de trazer insegurança na informação para o público em geral.

Palavras-chave: Pandemia; Direito dos Desastres; Natureza jurídica.

Eixo Temático: Sociedade e Ambiente (SA).

\section{INTRODUÇÃO}

O Brasil é um dos países que mais possui números de infectados e de vítimas pela Covid-19 por dia, este fato ressalta e corrobora com o argumento de que existe uma grande desigualdade em nosso território. Somado a isso, está a falta de organização para o combate a disseminação do vírus e a disseminação de notícias falsas, a chamada infodemia. Em paralelo a busca por produção de vacinas e a vacinação, existe uma outra "doença" que se expande em campos menos convencionais, os discursos.

Este combate às informações falsas, as denominadas fake news, têm se desenvolvido em um cenário de medos e incertezas, e muitas vezes totalmente desvinculado do comportamento sugerido pela ciência. Assim, na crise provocada

\footnotetext{
${ }^{1}$ Acadêmica do curso de Direito na Universidade Franciscana, gabriela.niazzi@hotmail.com ${ }^{2}$ Doutora em Direito pela UNISINOS. Mestre em Direito pela UFSM. Professora do Curso de Direito da Universidade Franciscana. E-mail: francielleagne@gmail.com
} 
pela Covid-19 informações e dados falsos ou sem comprovação científica tem gerado equívocos e tensionamentos entre a ciência e o Estado, como exemplos: tratamentos preventivos, utilização de máscara e distanciamento social (HENRIQUES; VASCONCELLOS, 2020). Nessa perspectiva, o acesso a informação qualificada e confiável é importantíssimo para que se possa mitigar e responder emergencialmente a um desastre.

Este tema se justifica por ser atual, relevante, inovador e transdisciplinar. Este trabalho se destaca, com relação ao seu ineditismo, visto que além de ser um tema que desperta interesse e é atual, poucas são as Universidades que investem no estudo e análises dos desastres, bem como com a sua gestão socioambiental do risco visando alternativas e possibilidades de gestão nas cidades.

Assim, este artigo tem como objetivo geral identificar a natureza jurídica da pandemia da Covid-19, analisando os possíveis impactos e consequências da infodemia na gestão socioambiental do risco.

\section{DIREITOS DOS DESASTRES E A COVID-19: UMA ANÁLISE SOBRE A NATUREZA JURÍDICA}

Em 2016, o Programa das Nações Unidas para o Meio Ambiente alertou sobre problemas ambientais globais emergentes, descrevendo um "aumento mundial no surgimento de doenças e epidemias, particularmente de zoonoses.(UNEP, 2016. p. 04) A qual, segundo a OMS, doenças zoonóticas são aquelas trasmissiveis de animais para a raça humana. Logo, são chamadas de desastres naturais, mas aonde que realmente está o "natural" nesta doença, como do covid-19. Seria por esta transmissão ter sido desencandeada através do morcego, que é um animal, ou por qualquer outro motivo inexplicável?

O fato é que não é de hoje o aumento, significativo, de doenças zoonóticas. Podem ser citadas diversas como: HIV, ebola, raiva, malária, entre outras (OMS, 2015). Mas a questão em si, é por qual motivo recebeu o adjetivo de natural, quando se trata, explicitamente, de um fator humano. Sendo assim, uma das causas de tantas pandemias (e com o tempo, a tendência é o aumento delas) são causadas pela intervenção humana. 


\section{QUFN}

Com a Covid-19, não poderia ter sido diferente, pórem, advém de riscos muito mais sérios, com o número de mortalidade muito maior. Segue abaixo o gráfico sobre a maior causa de morte no Brasil em fevereiro de 2021.

Figura 1 - Principal causa de morte no Brasil

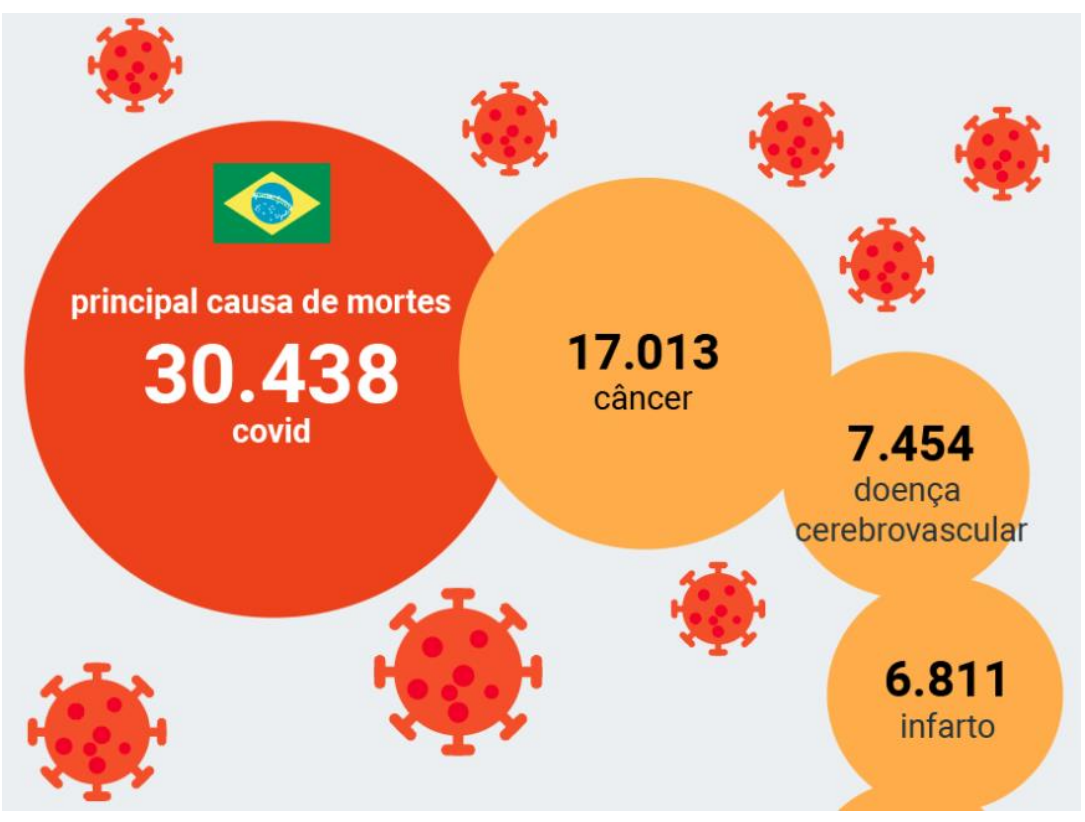

Fonte: https://www.poder360.com.br/coronavirus/em-fevereiro-covid-foi-a-maior-causa-de-morte-nobrasil/

Pode-se observar que a Covid-19 é responsável por 30.438 mortes no Brasil, em fevereiro de 2021, o que demonstra que ultrapassa e muito as outras doenças, como por exemplo: o câncer, doenças cerebrovasculares, infarto, dentre outras. Restando claro, o tamanho e o poder de transmissão (e, mortalidade) desse vírus.

Ainda, até o mês de agosto de 2021, chegou-se a marca de 591 mil pessoas mortas. O coronavírus, alcançou todas as classes, etnias, gêneros, idades e religiões, no entanto, a magnitude desta doença teve um grande impacto em países, regiões com maiores desigualdades sociais e econômicas.

De acordo com o relatório da Oxfam (2020, p. 05), 
A trajetória do vírus é uma fotografia das profundas desigualdades do país. Antes da Covid19, o Brasil tinha 40 milhões de trabalhadores informais e 11,9 milhões de desempregados, muitos sem proteção social. As expectativas apontam que o desemprego pós-pandemia pode aumentar para taxas de $15 \%$, com 16 milhões de desempregados. Ao redor de 5 milhões de moradias estão localizadas em favelas, em grande parte sem acesso a água tratada e saneamento básico e com alta densidade de pessoas por residência. $E$ isso quando a higienização e o distanciamento social são essenciais para evitar a propagação do vírus. A essas cifras se soma o racismo estrutural do país onde $75 \%$ dos mais pobres são pessoas negras (pretos e pardos, por definição do IBGE). Não surpreende que os números mostrem que as pessoas negras e pobres correspondam ao perfil de vítima mais comum da Covid-19 no Brasil, representando 6 de cada 10 mortes.

Quando se trata de direitos e desastres, as consequências desse vírus não são nada simples. Ou seja, quanto maior for a vulnerabilidade, maior serão as consequências do desastre. De acordo com a pesquisa Centre for Research on the Epidemiology of Disasters, perceberam que situações como essas, que necessitam de auxilios internacionais, extremamente imprevisiveis, podem ser considerados como uma pandemia:

Para este centro de pesquisa, ao menos um dos critérios que seguem deve ser preenchido para a configuração de um evento danoso à condição de desastre: (a) 10 ou mais mortes humanas (efetivas ou presumidas); (b) pelo menos 100 pessoas atingidas (necessitando de comida, água, cuidados básicos e sanitários; desalojados e feridos); (c) ter sido declarado estado de emergência; (d) ter havido um pedido de ajuda internacional (CARVALHO, 2020).

Sendo assim, mostra-se evidente que o coronavírus é considerado um desastre, onde todos os itens citado anteriormente correspondem aos fatos. No que diz respeito às mortes, está claro mais do que nunca, que essa pandemia será marcada para o resto da história da humanidade, embora a vacina esteja conseguindo salvar muitas pessoas e famílias. Neste ponto, que a ciência e a natureza jurídica se conectam, tanto por nestas cituações, como o covid, trazer mais inovações na área da saúde, infelizmente de maneira trágica, mas também, com um avanço em todas as outras áreas da sociedade, como a economia, educação, entre outros.

No gráfico abaixo, é possível visualizar as consequências da vacinação em relação as quedas da Covid-19. 
EDUCAÇÃO, SAÚDE

ETECNOLOGIA

26 A 28 DE OUTUBRO DE 2021

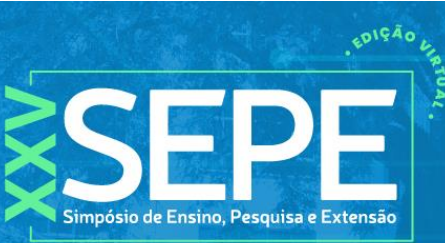

Figura 2 - Número de mortos no Brasil até agosto de 2021

Fonte: JHU CSSE COVID-19 Data · Última atualização: há 2 dias

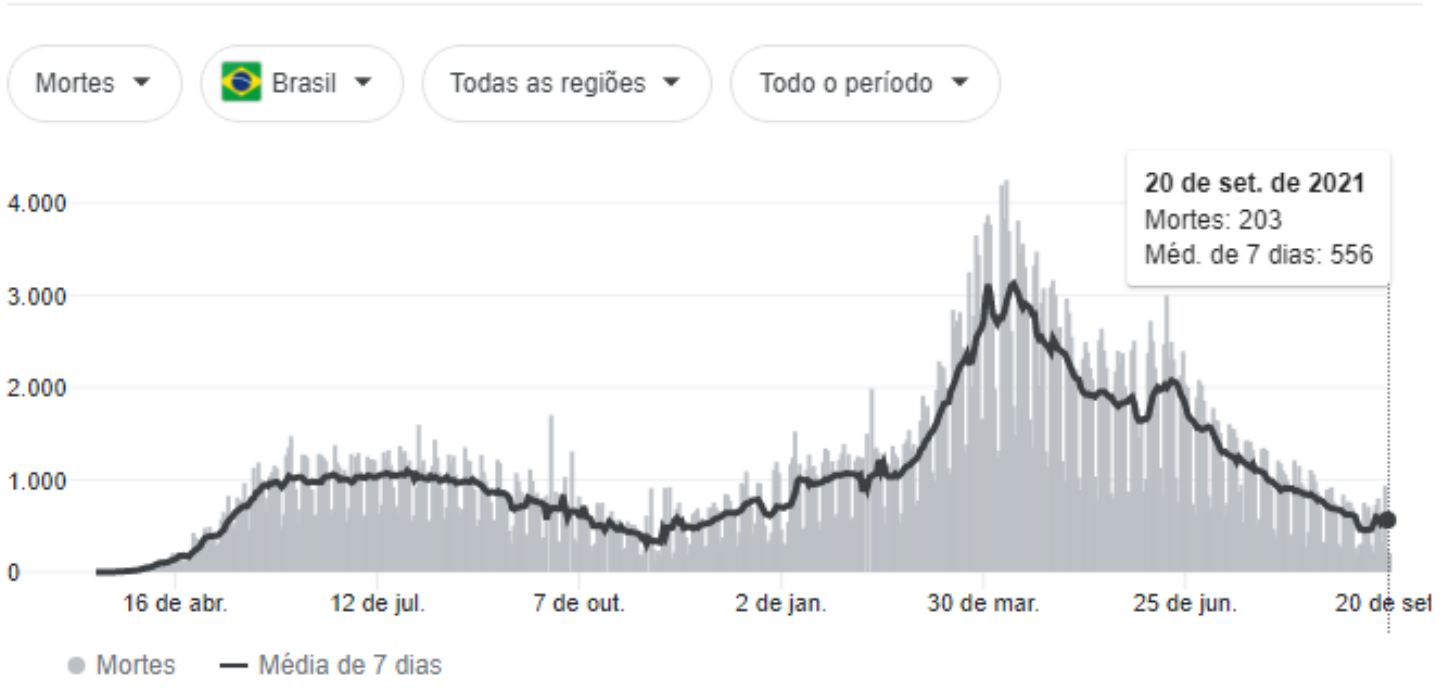

A cada dia novos casos informados desde o dia anterior são mostrados - $\underline{\text { Sobre esses dados }}$

円 Casos

Fontes: Wikipédia e outros . Última atualização: há 2 dias

Fonte:

https://www.google.com/search?q=numero+de+mortes+de+covid+no+brasil+ate+agosto+de+2021\&o $\mathrm{q}=$ numero+de\&aqs=chrome.1.69i57j69i59j0i512j0i433i512i3j0i512j0i433i512j0i512j0i433i512.2026j0j7 \&sourceid=chrome\&ie $=$ UTF- 8

Será que um dia iremos nos recuperar da vida que estamos vivendo hoje? Quantos anos demorará para a economia se reerguer? Como será que as famílias mais pobres conseguem viver dia após dias, com muitos sem empregos fixos?

Há muitos questionamentos sobre e como será a vida após esse desastre biológico. Soma-se a isso, uma avalanche de informações falsas (fake news) sobre a Covid-19. Temática que será abordada no próximo item. 


\section{A INFODEMIA COMO UMA PANDEMIA INVISÍVEL: OS IMPACTOS DAS FAKE NEWS NA GESTÃO SOCIOAMBIENTAL DO RISCO}

Em meio a pandemia do coronavírus, aconteceram outras situações que acabaram por confundir, e por vezes, atrapalhar a gestão do risco. Dentre eles, pode ser citado a infodemia, que nada mais do que um "bombardeamento" de informações, sendo elas verdadeiras ou falsas. Visto que a covid-19 é um assunto muito sério, que abrange o mundo todo, a infodemia tem sido um dos grandes vilões para o combate.

A medida que a tecnologia foi aumentando, e consequentemente a informação, no caminho houveram obstáculos. Da mesma maneira que em segundos uma informação, notícia, chega ao outro lado do mundo, as fake news também chegam.

Sobre as fake news é importante distinguir, pois nelas só existem mentiras e falsas informações, o que não corresponde $100 \%$ do conceito de infodemia. Está "notícia falsa", traduzida do inglês, só traz perturbação para quem quer o conhecimento de verdade, e o quanto pessoas lucram com esse tipo de conteúdo. Infelizmente, como o ser humano se interessa com o mais trágico, sendo eles transmitidos por reportagens, redes sociais, filmes, entre outros, a mídia e os meios de comunicações, sabem deste "ponto fraco", dessa forma, conseguem lucrar com esse tipo de atividade.

No entanto, entende-se que, esta disseminação de informações falsas poderia ocasionar uma grande divergência na vida das pessoas. Mas, e quando se trata de notícias no âmbito mundial, como resolver? No Brasil, as fake news não são consideradas crime, porém, existem alguns projetos que estão tramitando no Congresso Nacional à respeito do tema, como por exemplo, pode ser visualizado abaixo no artigo em tela:

Art. 287-A - Divulgar notícia que sabe ser falsa e que possa distorcer, alterar ou corromper a verdade sobre informações relacionadas à saúde, à segurança pública, à economia nacional, ao processo eleitoral ou que afetem interesse público relevante.

Pena - detenção, de seis meses a dois anos, e multa, se o fato não constitui crime mais grave.

$\S 1^{\circ}$ Se o agente pratica a conduta prevista no caput valendo-se da internet ou de outro meio que facilite a divulgação da notícia falsa:

Pena - reclusão, de um a três anos, e multa, se o fato não constitui crime mais grave. 
$\S 2^{\circ}$ A pena aumenta-se de um a dois terços, se o agente divulga a notícia falsa visando a obtenção de vantagem para si ou para outrem. (SENADO FEDERAL, 2017).

O artigo supracitado faz parte de um projeto de lei, podendo ele ser aprovado ou rejeitado. Tendo como objetivo principal, criminalizar a divulgação de notícia falsa, buscando proteger a vítima, sendo a sociedade como um todo. Este projeto de lei, requer o interesse público, com situações diferente, como: a notícia falsa divulgada pela internet causa aumento de pena.

No contexto da pandemia atual, a infodemia causa sérios problemas a saúde mental, e não pelo simples fato de saber uma "mentirinha", mas pelas pessoas não conseguirem mais distinguir o certo do errado. Do medo ser um causador de insônia, ansiedade, pânico, entre outras diversas consequências. Para isto, é preciso saber onde procurar estas informações.

De acordo com a OPAS (Organização Pan-Americana da Saúde) e a OMS (Organização Mundial da Saúde), é preciso buscar lugares confiáveis para obter a informação de forma adequada e a mais neutra possível, entre elas, se destacam alguns desses lugares: portal exclusivo da OPAS/OMS, orientações e ultimas pesquisas sobre a COVID-19 nas Américas (OPAS/OMS). Estes lugares citados recentemente, estão os mais próximos possíveis das equipes de saúde de diversos lugares, mostrando a situação real dos hospitais. Logo, a garantia de informação correta desses meios de comunicação possui um enorme porcentual.

Entende-se que um "nicho" desta pandemia, como a infodemia, fake news, vacinação, economia, entre outros, são tão responsáveis pela contaminação do vírus, quanto do desfecho do coronavírus. O que se pode dizer é que determinados fatores, podem agravar, como o caso da infodemia, pois, é preciso haver muito equilíbrio. Da mesma forma que a informação precisa ser fluida, ela precisa ser contida devido ao nível de "bombardeamento".

A infodemia leva ao esgotamento e ao cansaço das pessoas, que estão em casa, ou aquelas que só saem para trabalhar, porque o cansaço físico e mental, levam a baixa da imunidade o que nos torna sujeitos a todo e qualquer tipo de vírus e bactérias. Sendo assim, as pessoas acabam se distanciando dos fatos reais, por estarem sem rumo em quem acreditar, sem sanidade mental para viver no mundo de hoje. 
Estudos da China, indicam que o suporte social disponibiliza uma maior interação com outras pessoas que pode ser realizada através da atual tecnologia através do fornecimento mútuo de ajuda estando intimamente interligado com o nível de estresse, levando também a má qualidade de sono que por sua vez pode acarretar problemas no bem-estar do corpo e da mente, aumentando níveis de substâncias como o cortisol. Assim, pessoas desprovidas de tal estão suscetíveis a poderem adquirir consequências diversas que irão interferir na sua sanidade mental (FREITAS et al., 2021, p. 06).

Logo, pode ser visualizado, através do estudo supracitado que, os pesquisadores estão observando essa mudança no comportamento das pessoas devido as infodemias e fake news.

\section{METODOLOGIA}

A Teoria utilizada será a Teoria do Direito dos Desastres como sendo uma reflexão construtora do papel do Direito na gestão circular do risco, através do recorte epistêmico de Daniel Farber e Délton Winter de Carvalho. Seu método de abordagem é pragmático-sistêmico (ROCHA, 2004). Como método de procedimento, na pesquisa em tela será utilizada a análise bibliográfica e documental bem como a pesquisa de opinião com análise de discurso (respostas) e pesquisa de campo aplicada à Santa Maria - RS e região.

Como técnica de coleta de dados optou-se pela produção de fichamentos e resumos estendidos, tabelas para sistematização de dados obtidos em documentos e legislação correlata, entrevistas e diário de campo. Também serão realizadas reuniões semanais no Grupo de Estudos em Direito dos Desastres e Covid-19 para sistematização dos dados e materiais e fortalecimento da relação entre os pesquisadores, estudantes e sujeitos da pesquisa.

\section{RESULTADOS E DISCUSSÕES}

O projeto encontra-se em fase inicial de elaboração. As informações relacionadas a pesquisa em tela são abordadas no Grupo de Estudos denominado 
"Covid e Desastres" vinculado a Universidade Franciscana, que oportuniza o aprofundar do conhecimento sobre o Direito dos Desastres, a pandemia e os efeitos por ela causados.

\section{CONCLUSÃO}

O Brasil se encontra como um dos países que mais possui números de infectados e de vítimas por dia, o que ressalta e corrobora com todas as informações e dados que já foram demonstrados, de que existe uma grande desigualdade neste território, e somado a isso, um descaso e uma falta de organização para o combate a disseminação do vírus por parte do governo.

A infodemia pode ser caracterizada como um fator de ampliação do risco, que acaba dificultando a possibilidade de prevenção, ou mesmo de mitigação do desastre. Como por exemplo, fake news e dados falsos tem gerado equívocos e tensionamentos entre a ciência e o Estado, tais como: tratamentos preventivos, utilização de máscara e distanciamento social.

Resta claro que, a informação é importantíssima para a prevenção dessa doença de magnitude e consequências ainda incomensuráveis.

\section{AGRADECIMENTOS}

Agradecemos a Universidade Franciscana pelo apoio e financiamento do Projeto "A COVID-19 COMO DESASTRE BIOLÓGICO: Uma análise sobre a natureza jurídica do desastre e os impactos da infodemia na gestão socioambiental do risco na cidade de Santa Maria - RS" através da bolsa de iniciação científica Probic/Fapergs.

\section{REFERÊNCIAS}

AGNE TYBUSCH, Francielle Benini. et al. Relatório da pesquisa de opinião sobre a vacinação contra a Covid-19. Santa Maria, RS: Arco Editores, 2021. Disponível em: 
EDUCAÇÃO, SAÚDE

ETECNOLOGIA

26 A 28 DE OUTUBRO DE 2021
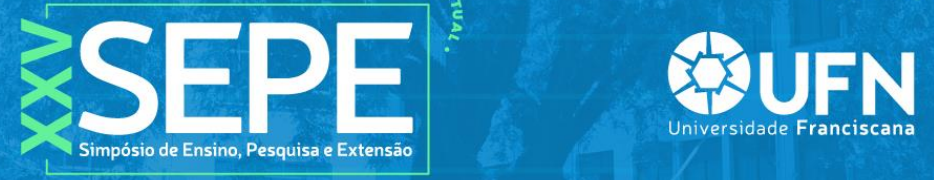

eb10305f7e07.filesusr.com/ugd/4502fa_366f285e43514bddb09f216b6901e9f7.pdf Acesso em: 22 jun. 2021.

FARBER, Daniel; CHEN, Jim; VERCHICK, Robert R. M.; SUN, Lisa Grow. Disaster Law and Policy. 2 ed. New York: Wolters Kluwer/Aspens Publishers, 2010.

HENRIQUES; VASCONCELOS. Crises dentro da crise: respostas, incertezas e desencontros no combate à pandemia da Covid-19 no Brasil. Estud. av. vol.34 no.99 São Paulo May/Aug. 2020 Epub July 10, 2020. Disponível em: https://www.scielo.br/scielo.php?script=sci_arttext\&pid=S0103-40142020000200025 Acesso em: 20 jun. 2021.

ROCHA, Leonel Severo. Três Matrizes da Teoria Jurídica. In: Epistemologia Jurídica e Democracia. São Leopoldo: Unisinos, 2004.

CARVALHO, Dalton Winter de; A natureza jurídica da Covid-19 como um desastre biológico. Revista Consultou Jurídico. 2020. Disponível em: https://www.conjur.com.br/2020-abr-13/delton-winter-natureza-juridica-covid-19desastre-biologico2. Acesso em: 21 setembro. 2021

FREITAS, Francisco Ricardo Nascimento. Saúde mental em tempos de isolamento social por Covid-19. Revista Saúde e Desenvolvimento Humano. $\begin{array}{llllll}\text { Canoas. } & \text { V.9, } & \text { n. } & 2, & 2021 & \text { Disponível }\end{array}$ https://revistas.unilasalle.edu.br/index.php/saude desenvolvimento/article/view/6954 Acesso em: 27 set. 2021.

OXFAM. QUEM PAGA A CONTA? Taxar a riqueza para enfrentar a crise da COVID-19 na América Latina e Caribe Disponível em: Acesso em: https://rdstationstatic.s3.amazonaws.com/cms/files/115321/1595622094Nota_informativa_da_Oxfa m_Quem_Paga_a_Conta.pdf. Acesso em: 26 abr. 2021. 
SENADO FEDERAL. PROJETO DE LEI DO SENADO № 473, DE 2017.

Senador Ciro Nogueira. Acesso em: 25 set. 2021. Disponível em: https://legis.senado.leg.br/sdleg-getter/documento?dm=7313311\&disposition=inline

UNEP. Emerging Issues of Environmental Concern. Nirobi: UNEP, 2016. Acesso em: 27 set. 2021. Disponível em: https://www.google.com/search?q=UNEP.+Emerging+Issues+of+Environmental+Co ncern.+Nirobi\%3A+UNEP\%2C+2016.+p.+04.\&oq=UNEP.+Emerging+Issues+of+Env ironmental+Concern.+Nirobi\%3A+UNEP\%2C+2016.+p.+04.\&aqs=chrome.0.69i59.35 5j0j7\& sourceid=chrome\&ie $=$ UTF -8 